\title{
Annexin V autoantibodies in rheumatoid arthritis
}

\author{
M I Rodríguez-García, J A Fernández, A Rodríguez, M P Fernández, C Gutierrez, \\ J C Torre-Alonso
}

\begin{abstract}
Objective-To investigate the occurrence of anti-annexin $V$ autoantibodies in sera of patients with rheumatoid arthritis to assess involvement with the disease and any relation to glucocorticoid treatment.

Methods-Anti-annexin V antibodies were measured by an enzyme linked immunosorbent assay (ELISA) which used the purified human recombinant protein as antigen.

Results-Concentrations of anti-annexin $V$ autoantibodies, predominantly of the IgG class, were significantly raised in sera from patients with rheumatoid arthritis compared to normal controls. This was not correlated with other indices of disease activity such as erythrocyte sedimentation rate or $\mathbf{C}$ reactive protein and was unrelated to glucocorticoid treatment.

Conclusions-Extracellular annexin V provides an antigenic stimulus for autoantibody production and its in vivo expression is independent of glucocorticoid control. Such autoantibodies may have a detrimental role in the arthritic condition by interfering with putative functions of annexin $V$, including collagen type II binding, inhibition of phospholipase $A_{2}$ activity, and Fc receptor activity.
\end{abstract}

(Ann Rheum Dis 1996;55:895-900)

Rheumatoid arthritis is a chronic disorder of connective tissue marked by extensive synovitis. Synovia become infiltrated by

Faculty of Medicine, University of Oviedo, E-33006 Oviedo, Spain: Department of Biochemistry and Molecular Biology M I Rodríguez-García M P Fernández

Hospital Central of Asturias, E-33006 Oviedo, Spain: Department of Rheumatology J A Fernández A Rodríguez

J C Torre-Alonso

Department of Immunology C Gutierrez

Correspondence to: J C Torre-Alonso Department of Biochemistry and Molecular Biology, Faculty of Medicine, University of Oviedo, E-33006 Oviedo, Spain. cells and by $B$ cells which secrete IgM, IgG, and IgA autoantibodies to tissue and circulating proteins. ${ }^{1}$ This autoimmune autoantigens that include human IgG-Fc fragments and extracellular cell matrix proteins such as collagens type I, II, IV, and V. Although these antibodies may have a physiological role in maintaining the integrity of self, their destructive potential in autoimmune disorders makes the identification of target antigens aetiologically important. ${ }^{1}$ A corollary of this premise is that autoantibodies to proteins which have a protective role in joint maintenance might further contribute to the disruption of joint homeostasis and immune regulation.

The annexins are a family of calcium dependent, phospholipid binding proteins involved in membrane trafficking and signal transduction and with a potential role as anti-inflammatory and growth regulatory agents. ${ }^{2}$ At least some of these properties may be due to the interaction of annexins with extracellular matrix proteins. Anchorin CII (chick annexin V) was first identified as a secreted, collagen type II binding protein ${ }^{3}$ that appears to mediate the adhesion of matrix vesicles to calcifying cartilage. ${ }^{4}$ Various annexins appear to be secreted by an exocytotic mechanism from cells in a collagen matrix and may thus play a role in remodelling the extracellular matrix. ${ }^{5}$ Annexins also effectively inhibit types I, II, and III phospholipase $\mathrm{A}_{2}$ by distinct mechanisms. ${ }^{6}$

The presence of raised concentrations of autoantibodies to human annexin I, V, and XI proteins (ANX1, ANX5, and ANX11) in various autoimmune diseases ${ }^{7-13}$ has received attention because of the anti-inflammatory role of these proteins and their apparent inducibility by glucocorticoids used for treatment. ${ }^{14}$ In rheumatoid arthritis, antiANX1 IgG was normal but IgM was stimulated following glucocorticoid treatment. ${ }^{15}$ Anti-ANX11 IgG autoantibodies directed at epitopes in the unique $\mathrm{N}$-terminus of this annexin were increased in rheumatoid arthritis and other autoimmune diseases. ${ }^{16}$ Anti-ANX5 autoantibodies in systemic lupus erythematosus and pre-eclampsia may increase the risk of thrombosis, ${ }^{1112}$ but their status and possible role in rheumatoid arthritis have not yet been examined. Since autoantibodies to type II collagen in rheumatoid arthritis play a primary role in cartilage destruction, ${ }^{17}$ the specific involvement of ANX5 and autoantibodies to it were considered relevant to the collagen immunity and inflammation in rheumatoid arthritis. response appears to be triggered by an array of

\section{Methods}

PATIENT DATA AND LABORATORY ANALYSES

Fifty one rheumatoid arthritis patients at the Hospital Central of Asturias fulfilled the American College of Rheumatology criteria ${ }^{18}$ based on clinical and laboratory data (table) and were included in a prospective study after giving informed consent. Their mean age was 64 years, $65 \%$ were female and $35 \%$ male, and the mean duration of illness was at least 6 years. Healthy controls were matched in both age and sex to the patient groups. Patient records included identification and medical history, with clinical assessment of the onset, form, and duration of illness, morning stiffness, tender joint score, and swollen joint score. Laboratory analyses included measurements of blood count, erythrocyte sedimentation rate (ESR, Westergren), rheumatoid factor (RF) by nephelometry, and C reactive protein by nephelometry. Radiographs were taken of 
Patient data. Population characteristics, clinical symptoms and laboratory tests are given for 51 patients diagnosed with rheumatoid arthritis and subcategorised according to glucocorticoid treatment dosage

\begin{tabular}{|c|c|c|c|c|c|c|}
\hline \multirow{2}{*}{ Feature } & \multirow{2}{*}{ Description } & \multirow{2}{*}{ Units } & \multicolumn{4}{|c|}{ Treatment subgroups of rheumatoid arthritis patients } \\
\hline & & & Subgroup 1 & Subgroup 2 & Subgroup 3 & Combined total \\
\hline Glucocorticoid & Dosage & $\mathrm{mg} \mathrm{d}^{-1}$ & 0 & $<7.5$ & $>7.5$ & Variable \\
\hline Patients & Number & $\mathrm{n}$ & 17 & 19 & 26 & 51 \\
\hline Age & Median (range) & years & $66(24-78)$ & $64(35-81)$ & $65(36-79)$ & $64(24-81)$ \\
\hline Sex distribution & Male/female & $\mathrm{n}$ & $4 / 13$ & $5 / 14$ & $8 / 7$ & $18 / 33$ \\
\hline Length of illness & Median (range) & years & $6(1-18)$ & $6(1-45)$ & $7(1-14)$ & $6(1-45)$ \\
\hline Morning rigidity & Time $>1 \mathrm{~h}$ & n & 3 & 7 & 11 & 21 \\
\hline Pain & Affected joints $>9$ & $\mathbf{n}$ & 2 & 10 & 12 & 24 \\
\hline Swelling & Affected joints $>6$ & $\mathbf{n}$ & 2 & 6 & 10 & 18 \\
\hline Rheumatoid factor & Mean $(S D)(n>30)$ & $\mathrm{IU} \mathrm{ml}^{-1}$ & $216(374)(7)$ & $204(198)(12)$ & $343(381)(13)$ & $249(321)(32)$ \\
\hline Creactive protein & Mean (SD) & $\mu \mathrm{g} \mathrm{ml}^{-1}$ & $10(16)$ & $19(20)$ & $45(48)$ & $24(33)$ \\
\hline ESR & Mean (SD) & $\mathrm{mm} / \mathrm{h}$ & $23(16)$ & $46(31)$ & $53(31)$ & $40(29)$ \\
\hline Anti-ANX5 titre* & Mean (SD) & ELISA & $243(227)$ & 283 (299) & $278(296)$ & $268(271)$ \\
\hline Anti-ANX5 titre* & Median (range) & ELISA & $145(10-676)$ & $159(38-1200)$ & $180(11-1029)$ & $162(10-1200)$ \\
\hline
\end{tabular}

ESR, erythrocyte sedimentation rate; IU, international units; $n$, number; SD, standard deviation; *, total antibody levels.

the hands and feet. Active rheumatoid arthritis was defined by the presence of six or more swollen joints plus two of the following criteria: more than nine tender joints, morning stiffness longer than $1 \mathrm{~h}$, or ESR greater than 30 $\mathrm{mm} / \mathrm{h}^{19}$ Patients excluded were those with infection or serious cardiac, pulmonary, or renal disease.

DATA ANALYSES

For the purposes of data analysis with respect to treatment, patients were categorised into three groups according to whether they received no glucocorticoid treatment, low dose prednisone (less than $7.5 \mathrm{mg}$ per day), or high dose prednisone (more than $7.5 \mathrm{mg}$ per day). The three rheumatoid arthritis patient groups were similar in age, sex, and duration of illness (table 1). The control donor group consisted of 49 healthy volunteers. Data comparisons used the SPSS and Microsoft EXCEL programs for microcomputers and included one way analysis
A

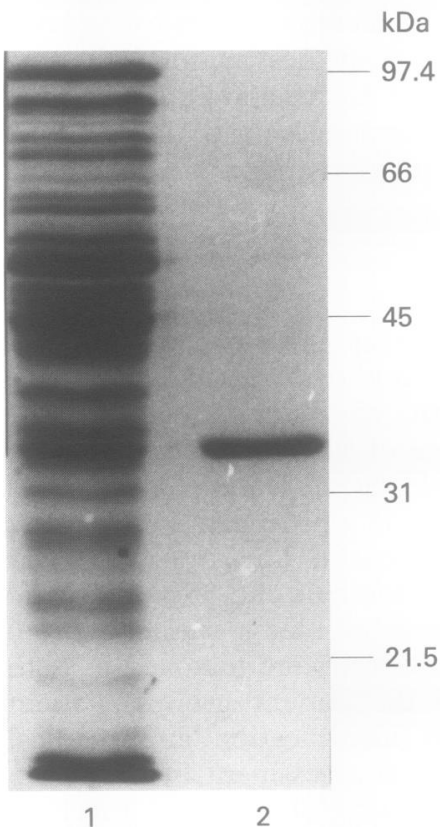

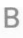

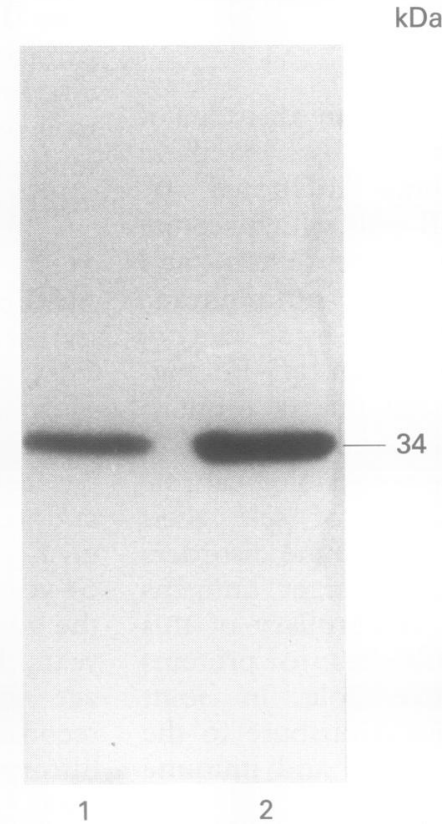

Figure 1 Purity of human annexin $V$ recombinant protein used for ELISA assays. The protein was produced and purified as described under Methods. Coomassie stained SDS-PAGE gels $(A$, left) show the resolution of proteins in whole homogenates following induction of plasmid containing bacterial cultures (lane 1) and of the liposome purified product (lane 2). The corresponding immunoblot (B, right) employed specific polyclonal antisera to identify the $34 \mathrm{kDa}$ bands in whole homogenate (lane 1) and purified protein (lane 2) as human annexin $V$. of variance (ANOVA), Student's two tailed $t$ test, $\chi^{2}$, and Wilcoxon rank sum test.

\section{EXPRESSION AND ISOLATION OF RECOMBINANT} ANX5

Recombinant human annexin $\mathrm{V}$ was expressed in Escherichia coli strain RB791 (American Type Culture Collection No 53622) transformed with plasmid pKA5H. This plasmid contained the entire coding DNA sequence of the human annexin $\mathrm{V}$ gene ${ }^{20}$ under the regulation of $t r c$ promoter. ${ }^{21}$ The coding portion of human annexin $\mathrm{V}$ was obtained from placental RNA by reverse transcriptase polymerase chain reaction (RT-PCR) and subcloned into the NcoI and HindIII sites of plasmid pKK233-2 (Pharmacia). Recombinant protein was purified from bacterial cell lysates following published procedures. ${ }^{22}$ Purity was assessed by sodium dodecyl sulphate polyacrylamide gel electrophoresis (SDS-PAGE) with Coomassie staining, and by immunoblotting with specific polyclonal antisera (fig 1), kindly provided by $\mathbf{R} B$ Pepinsky (Biogen Inc, Cambridge, MA, USA).

ENZYME LINKED IMMUNOSORBENT ASSAY (ELISA) Microwell plates (Immuno Maxisorp, Nunc Intermed, Roskilde, Denmark) were coated overnight at $4^{\circ} \mathrm{C}$ with $0.5 \mu \mathrm{g}$ per well recombinant human annexin $\mathrm{V}$ in $100 \mu \mathrm{l} 50$ $\mathrm{mM}$ carbonate/bicarbonate buffer, $\mathrm{pH}$ 9.6. After incubation, plates were washed four times with $200 \mu \mathrm{l}$ phosphate buffered saline (PBS), pH 7.2, containing $0.05 \%$ Tween 20 , and blocked with $5 \%$ milk powder in $200 \mu \mathrm{l}$ PBS-Tween 20. Plates were then washed twice again and dilutions of sera in blocking solution (1:8 to $1: 512$ ) were applied to microtitre wells. Duplicate wells containing $100 \mu \mathrm{l}$ of each dilution were incubated for $1 \mathrm{~h}$ at room temperature. Plates were washed three times with PBS-Tween 20 and wells were incubated for $1 \mathrm{~h}$ with $100 \mu \mathrm{l}$ of a solution containing goat antihuman antibody (IgG, IgM or total) alkaline phosphatase conjugate (Sigma) diluted 1:5000 in PBS-Tween 20. Microtitre plates were again washed and $100 \mu$ of 13.5 mM p-nitrophenolphosphate substrate added, with incubation in the dark for $15 \mathrm{~min}$ at room temperature. The reaction was terminated by addition of $100 \mu \mathrm{l} 1 \mathrm{~N} \mathrm{NaOH}$. Absorbence measurements at $405 \mathrm{~nm}$ were obtained with a 
Titertek Multiskan (EFLAB, Finland) ELISA plate reader. Blank values were subtracted from sample readings and results were expressed in ELISA units, defined as $\mathrm{AU}_{405}$ (sample) $\times$ dilution factor $\div$ reaction volume $(\mathrm{ml})$. Consistency was maintained in the ELISA by including two identical serum samples of high and low anti-annexin V titre in each plate and assay. Specificity was also tested by preincubating patient sera with fixed quantities of soluble annexin $\mathrm{V}$ in the range $0.5-10 \mu \mathrm{g}$ to block binding by $25-75 \%$, when compared to the control absorbence without competition.

\section{Results}

RAISED ANTI-ANX5 AUTOANTIBODIES IN RHEUMATOID ARTHRITIS

The mean anti-ANX5 autoantibody titre was measured by ELISA in sera from 51 rheumatoid arthritis patients compared to the 49 control subjects (fig 2). ELISA readings, expressed as the mean, were higher for rheumatoid arthritis patients than control subjects, at 268 (SD 271) $v 156$ (161) arbitrary units. The increase in anti-ANX5 autoantibodies in rheumatoid arthritis patients was significant $(P=0.016)$ by a two tailed $t$ test assuming unequal population variances.

ROLE OF GLUCOCORTICOID TREATMENT

The anti-ANX5 data from rheumatoid arthritis were reanalysed according to treatment subgroups in order to determine

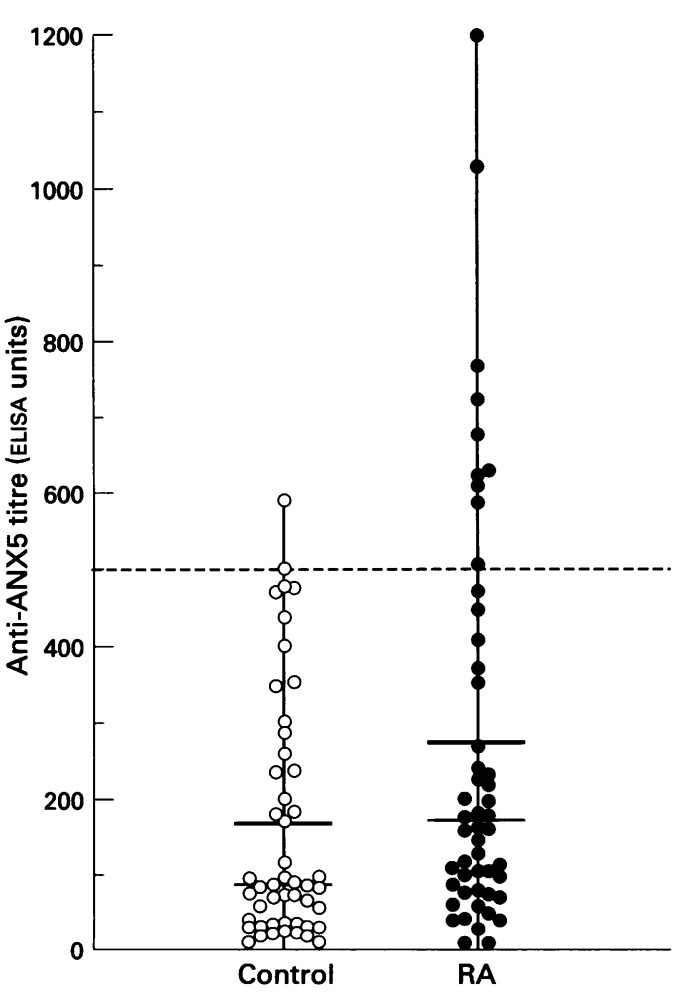

Figure 2 Anti-annexin $V$ autoantibody levels in rheumatoid arthritis patients and normal controls. ELISA readings were taken from sera of 49 healthy volunteers (empty circles) and 51 patients diagnosed with rheumatoid arthritis (filled circles) and expressed on the ordinate scale as arbitrary ELISA units. Solid horizontal lines mark the mean (bold) and median (thin) values for each group and the dashed line signifies the level corresponding to two standard deviations above the control mean. Vertical lines through the points span the full range of values. whether the increase in autoantibody was related to glucocorticoid treatment (fig 3). The mean (SD) values for the three subgroups of rheumatoid arthritis patients were 243 (227) units for untreated patients, 283 (299) for those receiving low dose glucocorticoid (less than $7.5 \mathrm{mg}$ per day), and 278 (296) for those receiving high dose glucocorticoid (more than $7.5 \mathrm{mg}$ per day). No significant difference was observed between the three subgroups using one way analysis of variance or a two tailed $t$ test, even when the two groups receiving glucocorticoid were compared as a single sample population to the untreated patient group.

\section{ANTIBODY TYPING}

Isotyping was performed to determine the class of antibody present in the sera of rheumatoid arthritis patients. The results (fig 4 ) showed a clear predominance of $\mathrm{IgG}$ compared to IgM, which remained in the normal range. This contrasted with previous findings of elevated IgM class autoantibodies to ANX1 in rheumatoid arthritis patients receiving high-dose glucocorticoid treatment ${ }^{15}$.

\section{CORRELATION WITH DISEASE INDICES}

The finding that glucocorticoid treatment was not a determinant of anti-ANX5 levels indicated a direct relation between ANX5 and disease status. Various indices were therefore measured to assess their correlation with anti-ANX5 titres in all 51 rheumatoid arthritis

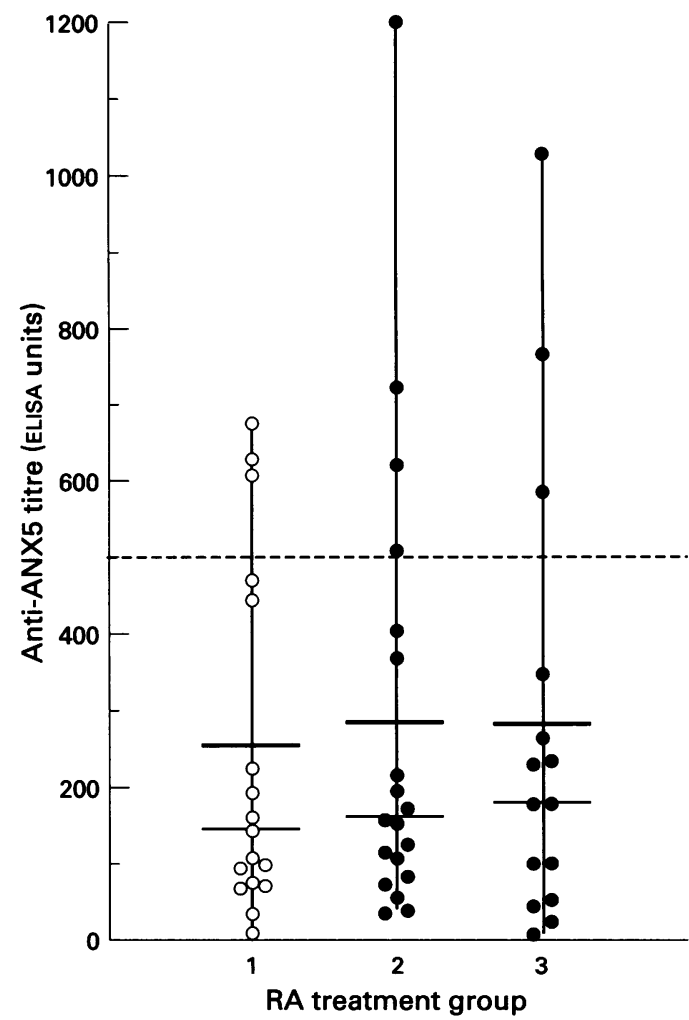

Figure 3 Anti-annexin $V$ autoantibody levels in rheumatoid arthritis patients grouped according to glucocorticoid treatment regimen. Group $1(n=17)$ glucocorticoid treatment regimen. Group $1(n=17)$
received no steroid treatment, group $2(n=19)$ received prednisone at less than $7.5 \mathrm{mg} / \mathrm{d}$, and group $3(n=15)$ received prednisone greater than $7.5 \mathrm{mg} / \mathrm{d}$. Solid horizontal lines mark the mean (bold) and median (thin) values for each group while vertical lines span the full range of values. The dashed line marks a threshold corresponding to two standard deviations above the control mean in fig 2. 


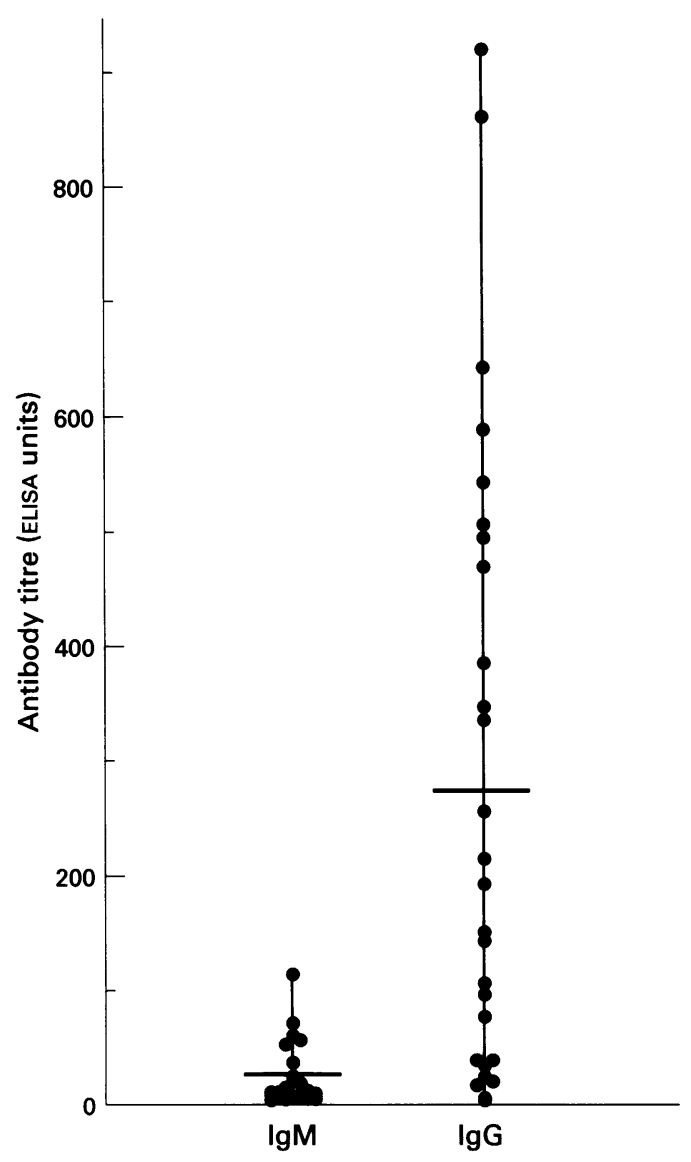

Figure 4 Classification of anti-ANX5 autoantibody isotype in rheumatoid arthritis. ELISA units are represented by filled circles to denote IgG or IgM class antibody observed in 27 rheumatoid arthritis patients. Horizontal solid lines mark the mean value for each group and vertical lines indicate the range of values.

patients. The mean values for rheumatoid factor [RF, 249 (321) $\mathrm{IU} \mathrm{ml}^{-1}$ ], C reactive protein [24 (33) $\mu \mathrm{g} \mathrm{ml}^{-1}$ ] and ESR [40 (29) $\mathrm{mm} / \mathrm{h}$ ] were characterised by a modest rise of anti-ANX5 titres (fig 5). However, none of these laboratory tests showed any significant positive correlation with anti-ANX5: $r<0.25$ with standard errors over $265 \mathrm{OD}_{405}$ units in predicting anti-ANX5 from RF, C reactive protein, or ESR values. Anti-ANX 5 titres were also grouped according to indices of clinical severity but there was no apparent correlation with the disease activity indices of morning rigidity, pain, or swelling.

\section{Discussion}

The prevalence of anti-ANX5 autoantibodies in autoimmune disease was first reported by Matsuda et al ${ }^{1112}$ who associated it with thrombotic risk in pre-eclampsia and systemic lupus erythematosus. The present finding of significantly raised anti-ANX5 IgG autoantibody titres in rheumatoid arthritis sera extends our knowledge of the immunochemical variables of this disease and may ultimately shed light on its aetiology and effective treatment. Since antibody levels were not correlated with any of the specific disease indices measured and did not appear to be a consequence of glucocorticoid treatment, their cause and effect remain to be clarified.

A perceived role for annexins as antiinflammatory ${ }^{14}$ and immunosuppressive ${ }^{23}$ agents implies that they may serve as normal protective regulators in the extracellular environment. The specific involvement of ANX 5 in collagen type II binding ${ }^{3}$ and bone calcification ${ }^{4}$ further suggests that its neutralisation by autoantibodies could have direct pathological consequences in rheumatoid arthritis. To the extent that ANX5 may mediate the interaction of collagen II with matrix vesicles, ${ }^{4}$ its neutralisation by autoantibodies might be expected to expose collagen II epitopes and interfere with bone calcification. Reduced ANX5 levels would also be expected to disinhibit the actions of known inflammatory mediators such as secretory phospholipase $\mathrm{A}_{2}$ and interleukin $1 .^{14}$

The association of anti-ANX5 antibodies with rheumatoid arthritis was independent of glucocorticoid treatment, in contrast to previous findings for $\mathrm{ANX} 1 .{ }^{15}$ Cell culture

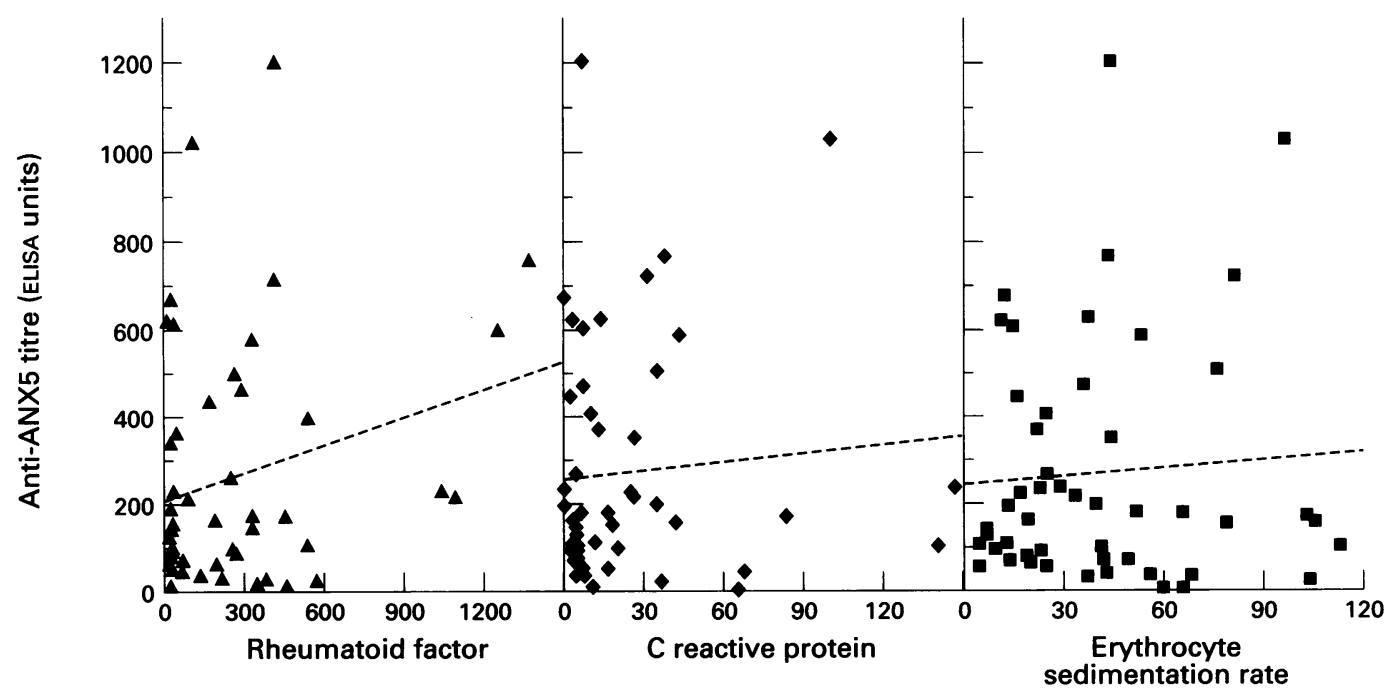

Figure 5 Correlation analysis between anti-ANX5 autoantibody titres and rheumatoid factor (RF, IU ml $\left.l^{1}\right), C$ reactive protein $\left(\mu \mathrm{g} \mathrm{ml} \mathrm{l}^{1}\right)$, and ESR $(\mathrm{mm} / \mathrm{h})$. Paired values of anti-ANX5 (ordinate scale) with either RF (triangles), $C$ reactive protein (diamonds), or ESR (squares) for all 51 rheumatoid arthritis patients are grouped into separate panels. Dots represent the calculated linear regression lines, for which the respective correlation coefficients $(r)$ were 0.25 for $R F, 0.08$ for $C$ reactive protein, and 0.07 for $E S R$. 
studies have shown the glucocorticoid inducibility of ANX1 and possibly ANX2, but not ANX5. ${ }^{24}{ }^{25}$ Differential regulation of ANX5 and ANX1 is consistent with the observation that annexin $\mathrm{V}$ genes lack the classical glucocorticoid regulatory elements ${ }^{2620}$ that exist in annexin I genes. ${ }^{27}$ However, since the responses of isolated cells to glucocorticoids have limited relevance for whole organisms, our observations on ANX5 during human glucocorticoid treatment provide important corroboration of the tissue culture findings. Thus the phenomenon of glucocorticoid resistance is more likely to be related to impaired induction of ANX1 than ANX5 as a mediator, ${ }^{28}$ and to the reduction of ANX1 levels by specific autoantibodies. ${ }^{29}$

The anti-ANX5 autoantibodies detected in rheumatoid arthritis were predominantly of the IgG class, consistent with an antigen driven mechanism of antibody formation. Since ANX5 has only six amino acids in its non-homologous N-terminus, epitopes in the annexin core region are probable targets. This contrasts with normal levels of anti-ANX1 IgG in rheumatoid arthritis and a raised IgM in response to prednisone. ${ }^{15}$ It also differs from ANX11 $1^{16}$ where IgG antibodies predominated in rheumatoid arthritis but were directed against the unique amino-terminal portion of the molecule. Regardless of the type of antibody or its precise antigenic epitopes, the extracellular levels of various annexins are likely to be compromised in rheumatoid arthritis.

The role of annexins in immune processes $^{1423}$ may be multifaceted as they have recently been found to act as Fc receptors, possibly involved in immunoglobulin binding to phagocytic cells. ${ }^{3031}$ Thus, in addition to binding their own specific autoantibodies at antigen affinity sites, they may also clear body fluids of other antibody complexes by binding their $\mathrm{Fc}$ regions to the surface of macrophages and leucocytes. In effect, the elimination of circulating annexins by their own autoantibodies might be expected to aggravate the autoimmune condition by impeding the clearance of other autoantibody complexes, including the $\mathrm{Fc}$ fragments comprising RF. However, that possibility does not seem to be consistent with the observed relation between anti-ANX5 and RF levels (fig 5).

Another recent study also observed a significant elevation of IgG-specific autoantibodies to both ANX5 and ANX6 in a smaller sample group of rheumatoid arthritis patients. ${ }^{32}$ The authors noted a similar lack of correlation in antibody levels with disease activity, RF level, or glucocorticoid treatment. However, negative correlations between IgG concentrations and patient age or glucocorticoid dosage were not confirmed by the present study, and may simply be related to the apparent decline of disease activity with age in their patient group.

Raised concentrations of autoantibodies to $A N X 5, A N X 1$, and $A N X 11$ in rheumatoid arthritis may reflect damage to collagen containing tissues such as synovial joints. The consequences for inflammatory responses involving secretory phospholipase $\mathrm{A}_{2}$, collagen metabolism, and antibody regulation would be expected to be detrimental, but assessment will require a better understanding of the physiological role of annexins. The identification of annexin $\mathrm{V}$ as an autoantigen in rheumatoid arthritis expands the scope of autoimmune processes in this disease and may ultimately lead to the development of techniques for controlling them.

This work was supported by a grant from the Fondo de Investigaciones Sanitarias (FISS 93/0633) that included fellowship support for MIR-G. We thank Dr Reginald O Morgan for help with production of the recombinant human annexin $\mathrm{V}$ protein and with manuscript preparation.

Williams DG Autoimmunity in rheumatoid arthritis. In: Klippel TH, Dieppe PA, eds. Rheumatology, section 3, chapter 9. London: Mosby Year Book, 1994:1-14.

2 Raynal P, Pollard HB. Annexins: the problem of assessing the biological role for a gene family of multifunctional calcium- and phospholipid-binding proteins. Biochim Biophys Acta 1994;1197:63-93.

3 Mollenhauer J, Bee JA, Lizarbe MA, von der Mark K. Role of anchorin CII, a 31,000-mol-wt membrane protein, in the interaction of chondrocytes with type II collagen. $\mathcal{F}$ Cell Biol 1984; 98:1572-8.

4 Kirsch T, Wuthier RE. Stimulation of calcification of growth plate cartilage matrix vesicles by binding to type-II and type-X collagens. $\mathcal{F}$ Biol Chem 1994;269:11462-9.

5 Lee TL, Lin YC, Mochitate K, Grinnell F. Stress-relaxation of fibroblasts in collagen matrices triggers ectocytosis of plasma membrane vesicles containing actin, annexins II plasma membrane vesicles containing actin, annexins II and VI, and be

$6 \mathrm{Kim}$ KM, Kim DK, Park YM, Kim CK, Na DS. Annexin I inhibits phospholipase A2 by specific interaction, not by substrate depletion. FEBS Lett 1994;343:251-5.

7 Hirata F, Del Camine R, Nelson CA, Axelrod J, Schiffmann $\mathrm{E}$, Warabi A, et al. Presence of autoantibody for phospholipase inhibitory protein lipomodulin, in patients with theumatic diseases. Proc Natl Acad Sci USA 1981;78:190-4.

8 Ikai K, Shimizu K, Kanauchi H, Ando Y, Furukawa F, Imamura $S$. The presence of autoantibody to lipocortin-I in mura S. The presence of autoantibody to lipocortin-1 in

9 Chung KF, Podgorski MR, Goulding NJ, Godolphin JL, Sharland PR, O'Connor B, et al. Circulating autoantibodies to recombinant lipocortin-1 in asthma. Respir Med $1991 ; 85: 121-4$.

10 Rivers JK, Podgorski MR, Goulding NJ, Wong E, McGrath JA, Flower RJ, et al. The presence of autoantibody to recombinant lipocortin-I in patients with psoriasis and psoriatic arthritis. Br ₹ Dermatol 1990;123:569-72.

11 Matsuda J, Gotoh M, Saitoh N, Gohchi K, Tsukamoto M, Yamamoto T. Anti-annexin antibody in the sera of patients with habitual fetal loss or preeclampsia. Thromb Res 1994; 75:105-6.

12 Matsuda J, Saitoh N, Gohchi K, Gotoh M, Tsukamoto W. Anti-annexin $\mathrm{V}$ antibody in systemic lupus erythematosus
patients with lupus anticoagulant and/or anticardiolipin patients with lupus anticoagulant and

13 Pruzanski $W$, Goulding NJ, Flower RJ, Gladman DD, Urowitz MB, Goodman PJ, et al. Circulating group II phospholipase A2 activity and antilipocortin antibodies in systemic lupus erythematosus-correlative study with disease activity. $\mathcal{F}$ Rheumatol 1994;21:252-7.

14 Flower RJ, Rothwell NJ. Lipocortin-1 - cellular mechanisms and clinical relevance. Trends Pharmacol Sci 1994;15:71-6.

5 Goulding NJ, Podgorski MR, Hall ND, Flower RJ, Browning IL Pepinsky RB, et al. Autoantibodies to recombinant ing JL, Pepinsky RB, et al. Autoantibodies to recombinant lipocortin-1 in rheumatoid arthritis and system

16 Misaki Y, van Venrooij WJ, Pruijn GJM. Prevalence and characteristics of anti-56K/annexin XI autoantibodies in systemic autoimmune diseases. $\mathcal{F}$ Rheumatol 1995;22:97102.

17 Karopoulos C, Rowley MJ, Handley CJ. Intrasynovial levels of sulphated glycosaminoglycans and autoantibodies to type II collagen in rheumatoid arthritis: a correlative analysis. Rheum Int 1993;13:15-20.

18 Arnett FC, Edworthy SM, Bloch DA, Shane DA, Fries JF, Cooper NS, et al. The American Rheumatism Association 1987 revised criteria for the classification of rheumatoid arthritis. Arthritis Rheum 1988;31:315-24.

19 Pinals RS, Masi AT, Larsen RA, The Subcommittee for Criteria of Remission in Rheumatoid Arthritis of the American Rheumatism Association Diagnostic and Therapeutic Criteria Committee. Preliminary criteria for remispeutic Criteria Committee. Preliminary criteria for remission in the

20 Fernandez MP, Morgan RO, Fernandez MR, Carcedo MT. The gene encoding human annexin $V$ has a TATA-less promoter with a high G+C content. Gene 1994;149:25360 
21 Amann E, Ochs B, Abel K-J. Tightly regulated tac promoter vectors useful for the expression of unfused and fused proteins in Escherichia coli. Gene 1988;69:301-15.

22 Burger A, Berendes R, Voges D, Huber R, Demange P. A rapid and efficient purification method for recombinant rapid and efficient purification method for recombinant 329:25-8.

23 Sakata T, Iwagami S, Tsuruta Y, Suzuki S, Suzuki R. Study of natural lipocortin I-a potent mediator for macrophage-mediated immunosuppression in tumorbearing mice. $\mathcal{F}$ Immunol 1993;151:4964-72.

24 Peers SH, Smillie F, Elderfield AJ, Flower RJ. Glucocorticoid and non-glucocorticoid induction of lipocortins (annexins) 1 and 2 in rat peritoneal leucocytes in vivo. $\mathrm{Br} f$ Pharmacol 1993;108:66-72.

25 Suarez F, Rothhut B, Comera C, Touqui L, Marie F R, Silve C. Expression of annexin I, annexin II, annexin V, and annexin VI by rat osteoblasts in primary culture - Stimulation of annexin I expression by dexamethasone. $\mathcal{F}$ Bone Miner Res 1993;8:1201-10.

26 Fernandez M P, Fernandez M R, Morgan R O. Structure of the gene encoding anchorin CII (chick annexin V). Gene $1994 ; 141: 179-186$
27 Kovacic RT, Tizard R, Cate RL, Frey AZ, Wallner BP. Correlation of gene and protein structure of rat and human lipocortin I. Biochemistry 1991;30:9015-21.

28 Podgorski MR, Goulding NI, Hall ND, Flower RJ, Maddison PJ. Autoantibodies to lipocortin-1 are associated with impaired glucocorticoid responsiveness in rheumatoid arthritis. $\mathcal{F}$ Rheumatol 1992;19:1668-71.

29 Morand EF, Jefferiss CM, Dixey J, Mitra D, Goulding NJ. Impaired glucocorticoid induction of mononuclear leukocyte lipocortin-1 in rheumatoid arthritis. Arthritis Rheum 1994;37:207-11.

30 Goulding NJ, Guyre PM. Lipocortin 1 binding to human leukocytes correlates with its ability to inhibit IgG interactions with Fc gamma receptors. Biochem Biophys Res Commun 1993;192:351-8.

31 Kristoffersen EK, Ulvestad E, Bjorge L, Aarli A, Matre R. Fc-gamma-receptor activity of placental annexin II. Scand f Immunol 1994;40:237-42.

32 Dubois T, Bisagni-Faure A, Coste J, Mavoungou E, Menkes C J, Russo-Marie F, et al. High levels of antibodies to annexins $\mathrm{V}$ and $\mathrm{VI}$ in patients with rheumatoid arthritis. $\mathcal{f}$
Rheumatol $1995 ; 22: 1230-4$.


O 